\title{
Characterization of expansive soils treated with lignosulfonate
}

\author{
Rama Vara Prasad Chavali ${ }^{*}$ (1) and B. Reshmarani
}

\author{
${ }^{*}$ Correspondence: \\ rvprasad@vrsiddhartha.ac.in \\ Department of Civil \\ Engineering, Velagapudi \\ Ramakrishna Siddhartha \\ Engineering College, \\ Vijayawada 520007, India
}

\begin{abstract}
The current study examines the potential of lignosulfonate to enhance the engineering behavior of two locally available expansive soils. The expansive soils were collected from Vijayawada and Amaravathi, located in the Capital Region of Andhra Pradesh, India. The soils were treated with four different percentages $(0.5,1,2$, and 4$)$ of lignosulfonate and were allowed to interact for 7 and 28 days. A series of laboratory tests such as unconfined compressive strength, cation exchange capacity and scanning electron microscopy were carried out on the soil specimens. The results indicated that lignosulfonate has significant influence on the strength behavior of expansive soils. The amount of fines content present in soils defines the optimum percentage of lignosulfonate. Lignosulfonate treatment resulted in reduced negative surface charge of soils and formation of Polymer chain microstructure along with flocculated or aggregated particle microstructure, which may attribute to the enhanced strength of the expansive soils.
\end{abstract}

Keywords: Expansive soil, Lignosulfonate, Unconfined compressive strength (UCS), Cation exchange capacity (CEC), Scanning electron microscopy (SEM)

\section{Introduction}

Nowadays, urbanization and industrialization are the two most important processes worldwide. These processes are associated with huge consumption of natural resources as well as enormous production of industrial by-products. In view of the environmental problems posed by these materials, there is an urgency to recycle and/or reuse the by-products in huge amounts. On the other hand, subgrade properties are considered to be essential pavement performance parameters. The black cotton soil deposits, cover extensive areas in India, are associated with inferior subgrade characteristics such as low strength and resistance to deformation under load. Soil stabilization is considered as an effective solution for sustainable improved performance of subgrades. The two most commonly used traditional chemical stabilization methods are lime and cement stabilization. In light of environmental and economic concerns, there is a need to upgrade traditional stabilization techniques with available waste materials. Thus, the present study focused on effective utilization of lignosulfonate, an industrial by-product, to meet the ever increasing demand for the subgrade stabilization materials. 
Lignosulfonate belongs to a family of lignin based organic polymers derived as a waste by-product from the wood and paper processing industry. Currently, the total annual worldwide production of lignosulfonates is approximately 1.8 million tons [4]. Lignosulfonates are being utilized for various applications such as dispersant, concrete additive, flocculant, metal absorbant, dust suppressant in mining, anti-oxidant, fertilizer and binders in the construction etc. [3, 4, 9, 11, 18, 22, 35]. Though lignosulfonates are being utilized in many applications, being an environmental friendly, non-corrosive and non-toxic chemical; still there is a lot of scope for mass consumption in geotechnical applications [20]. In view of this, the potential of lignosulfonate as a soil stabilizer has been studied by examining shear strength, penetration resistance, erosion resistance, compaction characteristics and durability [13, 24, 26, 31, 32]. The enhancement of geotechnical characteristics of lignosulfonate treated soils have been reported by many researchers (Table 1). For example, Puppala and Hanchanloet [24] evaluated the potential of lignosulfonate along with sulfuric acid in soil stabilization. They found that it enhanced both the physical and engineering characteristics of soil which were attributed to the combined chemical reactions of lignosulfonate and sulfuric acid with soil. Santoni et al. [26] revealed the improvement of unconfined compressive strength of silty sand upon treatment with lignosulfonate. Vinod et al. [34] revealed improvement in erosional parameters such as critical shear stress and coefficient of soil erosion which were mainly ascribed to the reduction of the double layer thickness by the neutralization of surface charges of the clay particles and the formation of more stable particle clusters by polymer bridging. Indraratna et al. [14] found that the clay mineralogy plays an important role in obtaining significant enhancement of engineering behavior of lignosulfonate treated soil. Koohpeyma et al. [15] reported improvement in erosion resistance of clayey sand significantly. Ta'negonbadi and Noorzad [30] reported an increase in stiffness and

Table 1 Recent attempts to improve the geotechnical characteristics of soils with lignosulfonate

\begin{tabular}{lll}
\hline Soil type & Outcome & Remarks \\
\hline Loess soil & Improvement in unconfined compressive strength & Li et al. [17] \\
Expansive soil & Reduction in swelling & Alazigha et al. [2] \\
Dispersive clay & Reduction in depressiveness & Vakili et al. [33] \\
Expansive clay & Reduction in swelling and swelling pressure & Noorzad and Ta'negonbadi [21] \\
Lateritic soil & Increase in unconfined compressive strength and marginal & Ravishankar et al. [25] \\
Clayey soil & improvement in CBR & \\
Lateritic soil & Increase in stiffness and unconfined compressive strength & Ta'negonbadi and Noorzad [30] \\
Sand-clay mixture & Reduces the permittivity and increases strength & Shivashankar et al. [28] \\
Silty soil & Effective to achieve optimum density at less energy & Sezer et al. [27] \\
Sandy silt & Improvement in shear strength & Blanck et al. [5] \\
Clayey sand & Reduction in erodibility & Chen et al. [7] \\
Clayey soil & Increase in strength whereas less moisture resilience & Koohpeyma et al. [15] \\
Clay soil & Increase in stiffness & Maskell et al. [19] \\
Erodible soil & Improvement in erosional parameters such as critical shear & Indraratna et al. [14] \\
Silty sand & stress and coefficient of soil erosion & \\
Clayey soil & Improvement in strength & Santoni et al. [26] \\
\hline
\end{tabular}


unconfined compressive strength of lignosulfonate treated clayey soil and attributed this enhancement to the electrostatic reaction between the mixture of lignosulfonate-water and soil particles. Li et al. [17] testified that the reduction in the thickness of the electric double layer of particles and silica-carbonate cementations resulted in an increased strength and reduction of energy dissipation in lignosulfonate treated loess.

Although a good amount of research has been conducted in the recent past to investigate the effect of lignosulfonate on behaviour of soils, it was not until recently that Alazigha et al. [1, 2], performed systematic studies aimed at determining whether lignosulfonate can improve the engineering behavior of expansive soils. This indicates an additional research is needed to clarify the influence of lignosulfonate on the geotechnical characteristics of expansive black cotton soil. Thus, in the present study, a series of experiments including unconfined compressive strength, cation exchange capacity and scanning electron microscopy were carried out to determine the behaviour of lignosulfonate treated expansive black cotton soils.

\section{Materials and methods}

\section{Expansive soil}

In this study, two expansive clayey soils were collected from Vijayawada (Latitude: $16^{\circ}$ $31^{\prime} \mathrm{N}$ \& Longitude: $80^{\circ} 39^{\prime} \mathrm{E}$ ) and Amaravathi (Latitude: $16^{\circ} 32^{\prime} \mathrm{N}$ \& Longitude: $80^{\circ}$ $31^{\prime}$ E) located in the capital region of Andhra Pradesh, India. Both the samples were predominant with montmorillonite mineral. All natural soil samples were oven dried, crushed and sieved through $425 \mu$ sieve prior to experimentation. The physical properties of soils are given in Table 2.

\section{Lignosulfonate}

Calcium lignosulfonate, an amorphous light-yellow-brown powder, used in the present study was purchased from the local market. It is available in both solid and liquid forms, which contains carbon $(\mathrm{C})$, oxygen $(\mathrm{O})$, sulfur $(\mathrm{S})$, and sodium $(\mathrm{Na})$ [34]. Lignosulfonate is water soluble under any $\mathrm{pH}$ value but not dissolvable in organic solvents [10]. It is

Table 2 Index properties of selected soil samples

\begin{tabular}{lll}
\hline Property & Vijayawada soil & Amaravathi soil \\
\hline Color & Black brownish clay & Brownish clay \\
Liquid limit & $75 \%$ & $46 \%$ \\
Plastic limit & $33 \%$ & $25 \%$ \\
Plasticity Index (\%) & $42 \%$ & $21 \%$ \\
Specific gravity & 2.6 & 2.61 \\
Sand content & $4 \%$ & $13 \%$ \\
Fines passing through 75 micron sieve $^{3}$ Proctor density $\left(\mathrm{kN} / \mathrm{m}^{3}\right)$ & $96 \%$ & $87 \%$ \\
Maximum dry density $\left(\mathrm{kN} / \mathrm{m}^{3}\right)$ & 18.50 & 19.71 \\
Optimum moisture content (\%) & 14.20 & 16.90 \\
Free swell index & $19 \%$ & $18 \%$ \\
Degree of expansiveness & $70 \%$ & $40 \%$ \\
\hline
\end{tabular}


lignin-based with a molar mass of 4600 to $398,000 \mathrm{~g}$ and a molecular weight from 800 to $100,000[16]$.

\section{Sample preparation}

\section{Unconfined compression strength $\left(q_{u}\right)$ test}

Unconfirmed compression testing imposes uniaxial compression conditions on a soil sample and is used for the determination of expansive soil of the un-drained shear strength. Unconfined compression strength test was conducted on two different soil samples, one Vijayawada and the second Amravati soil according to ASTM D2166, 2013. The preparation of stabilized samples, different percentages of lignosulfonate including $0.5 \%, 1 \%, 2 \%$ and $4 \%$ of the dry mass of the soil were initially mixed with water. The soil specimens were prepared for maximum dry density and optimum moisture content which may specify the in situ moisture content based on the field requirements. The amount of water corresponding to optimum moisture content and maximum dry density for soils stabilized with predetermined lignosulfonate percentages was obtained from the standard Proctor compaction test (ASTM D698 2012). The soil and water-lignosulfonate mixture was compacted in five layers using static compaction and the prepared samples $(38 \mathrm{~mm}$ diameter by $76 \mathrm{~mm}$ height) were kept in the sealed double layer plastic covers in a room with controlled temperature under different interaction periods ( 0,7 and 28 days). After completion of interaction period, the sample is centered between bottom platen and upper platen of a mechanical load frame without any cover or lateral support. The loading applied in such a manner to produce an axial strain at a rate of $1 \%$ per minute. Load and deformation readings are noted until the failure of the sample or a reduction of $20 \%$, whichever is smaller.

\section{Cation exchange capacity (CEC)}

Methylene blue titration (MB) method has been adopted for determining the cation exchange capacity of Vijayawada and Amravati soil. Dominijanni et al. [12] reported that the standard ammonium displacement method underestimate the CEC value to a great extent, whereas an acceptable CEC value was delivered by the MB titration method. As a result, the MB titration method, which is used in industry for routine quality controls, was used in this investigation, despite its apparently more limited accuracy. The represented soil samples collected at the end of the UCS test were oven dried at $60{ }^{\circ} \mathrm{C}$. The dried samples were powdered and were used for carrying out MB titration method.

In this testing, about $2 \mathrm{~g}$ of dry soil from the 28 days tested UCS samples passing through $425 \mu \mathrm{m}$ sieve was mixed with $10 \mathrm{~mL}$ of water as soil solution in a $50 \mathrm{~mL}$ beaker. For methylene blue solution, $10 \mathrm{~g}$ of methylene blue dye powder was mixed thoroughly with $1 \mathrm{~L}$ water. After each addition of methylene blue solution to the soil suspension it was mixed by stirrer for $1 \mathrm{~min}$, and then a drop of slurry is placed on a filter paper with a pipette for visual examination. At the first appearance of the blue-green halo spot, titration is stopped and test was repeated till the results are consistent. At this point, CEC is determined by the following formula [8]:

$$
C=\frac{100}{W m} * V c c * N m b
$$


where $C$ is the cation exchange capacity (meq/100 g clay), $W m$ is the weight of clay specimen, $\mathrm{g}, V c c$ is the volume of methylene blue titrant, $\mathrm{mL}$, and $N m b$ is the normality of the methylene blue substance, $\mathrm{meq} / \mathrm{mL}$.

$$
N m b=\frac{\text { weight of methylene blue }(g)}{320} * \frac{100-X}{100}
$$

where $X$ is the moisture content of methylene blue substance, \%.

\section{Field emission scanning electron microscopy (SEM) analysis}

Field emission scanning electron microscopy tests have been done to inspect the topographical microstructural changes in the lignosulfonate treated soils. FEI Apreo LoVac microscope with unique revolutionary compound lens without beam technology was used to obtain high resolution of $1.0 \mathrm{~nm}$ images of soil microstructure. The representative soil samples were mounted onto the double-sided carbon tape glued to the flat surface of SEM stub and then coated with a thin layer of gold for $120 \mathrm{~s}$ using the Leica Ultra Microtome EM UC7 sputter coater prior to scanning. The SEM images shown in the study were selected from numerous images taken at different magnifications of the selected soil samples. The micrographs shown are those with the magnifications that best demonstrate the distinctive microstructure of the soil.

\section{Results and discussions}

\section{Unconfined compressive strength results}

Results of unconfined compressive strength testing on untreated and treated expansive soils at different LS contents and interaction periods were presented in Fig. 1. In general, the $q_{u}$ of montmorillonitic soils mainly arises from the viscous resistance generated by the viscous diffuse double-layer water to the shear deformation [29]. The figure depicts that the LS treatment enhanced the $q_{u}$ of both the soils at all interaction periods. In case of VJS, an increase in the amount of LS resulted in an increase in qu. In case of AMS, an

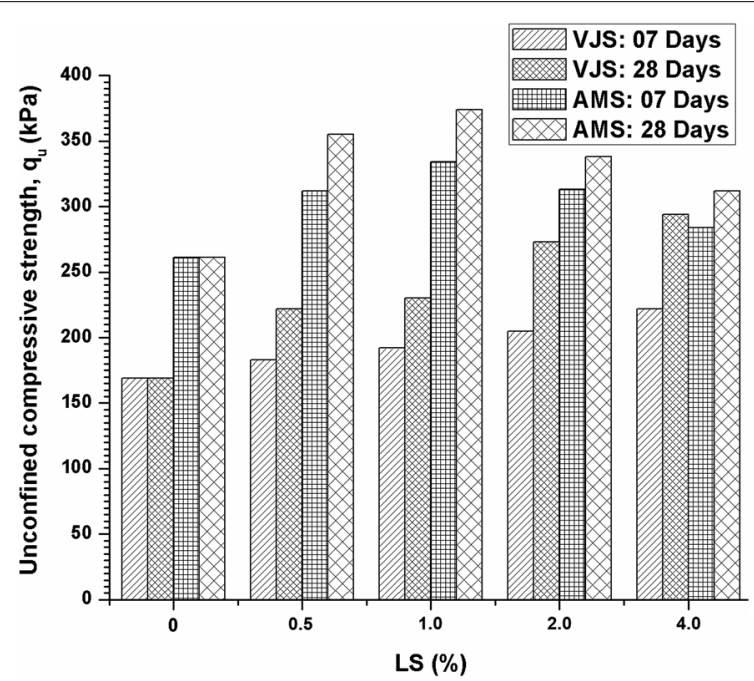

Fig. 1 Unconfined compressive strength of lignosulfonate treated soils 
increase in $q_{u}$ was observed with increasing percentages of LS from 0 to 1 whereas further addition of LS percentage more than 1 lead to reduction in $q_{u}$. The improvement of $q_{u}$ of LS treated soils can be attributed to the reduced negative surface area of clay minerals and subsequent formation of stable aggregation. The variations in terms of strength with the addition of strength gain can be explained in terms of amount of fines. The VJS consists of higher amount of fines (96\%) which required higher amount of lignosulfonate polymer chains to bind clay particles. The AMS consists of relatively lower amount of fines (87\%), which may require fewer amounts of lignosulfonate polymer chains. The extra polymer chains create reciprocal repulsive forces between the charged parts of the admixture [1] which may resulted in reduction in $q_{u}$. Results of cation exchange capacity of LS treated soils supports the enhancement of strength (Fig. 2).

\section{Cation exchange capacity test results}

Cation exchange capacity defines the ability of a soil to absorb and exchange cations [23]. Figure 3 depicts the changes in CEC of soils due to the addition of LS. It was evident from the graphs that the CEC of LS stabilized soils are lower than those of untreated soils. In case of VIS, CEC value of soil decreased linearly with the increments of LS from 0.5 to 4 . However, the CEC decreased considerably up to $1 \%$ LS in case of AMS, thereafter, the reduction in CEC found to be negligible. The positively charged LS is adsorbed on the surface of negatively charged clay particles during the interaction between soil and LS and subsequently resulting in the reduction of CEC as well as double layer thickness [34].

\section{Field emission scanning electron microscopy results}

Microstructure characteristics of untreated and treated expansive soils at different LS contents and interaction periods were presented in Figs. 3 and 4. Undulating filmy particle like microstructure can be seen from the micrograph of natural VJS. Figure 2a depicts that the microstructure of VIS remained same after the treatment with $0.5 \%$ LS. Higher amounts of lignosulfonate treatment significantly modified the microstructure of the VIS. Untreated VIS clearly reflected more void spaces whereas lignosulfonate treated VIS showed more dense and flocculated microstructure. This can be possibly attributed

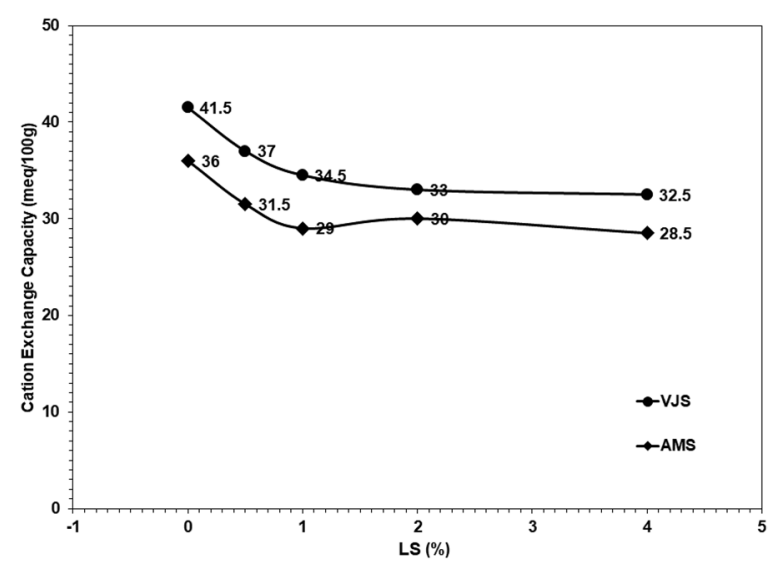

Fig. 2 Cation exchange capacity of lignosulfonate treated soils 


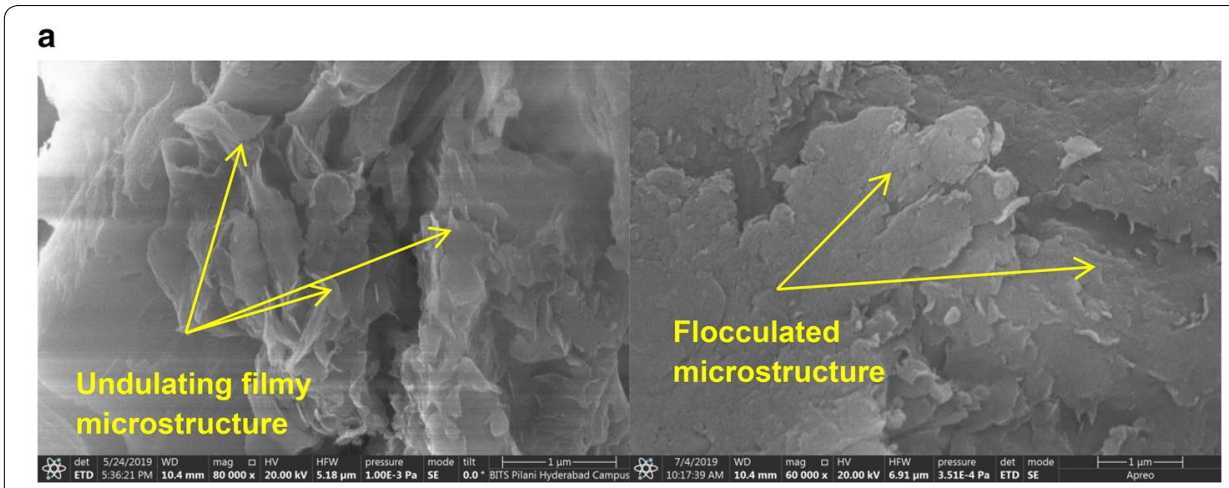

b

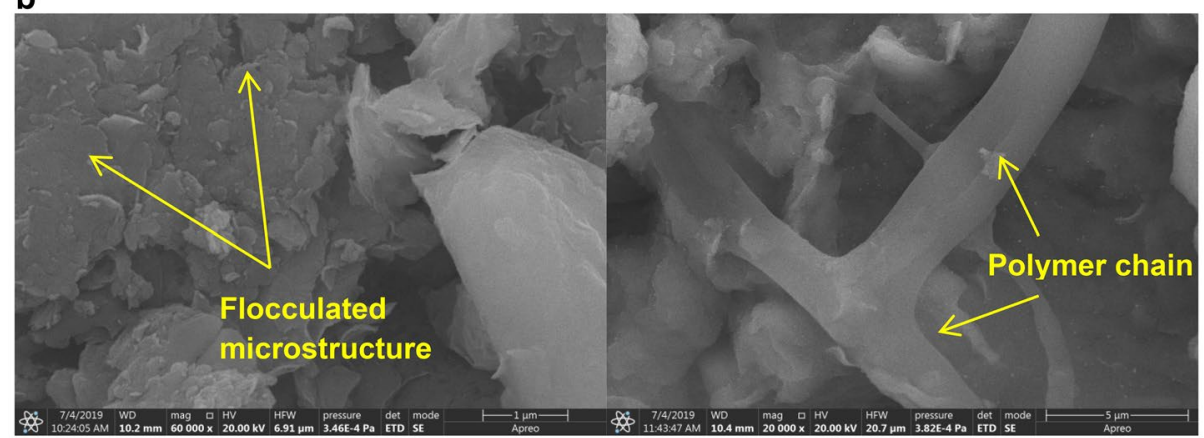

C

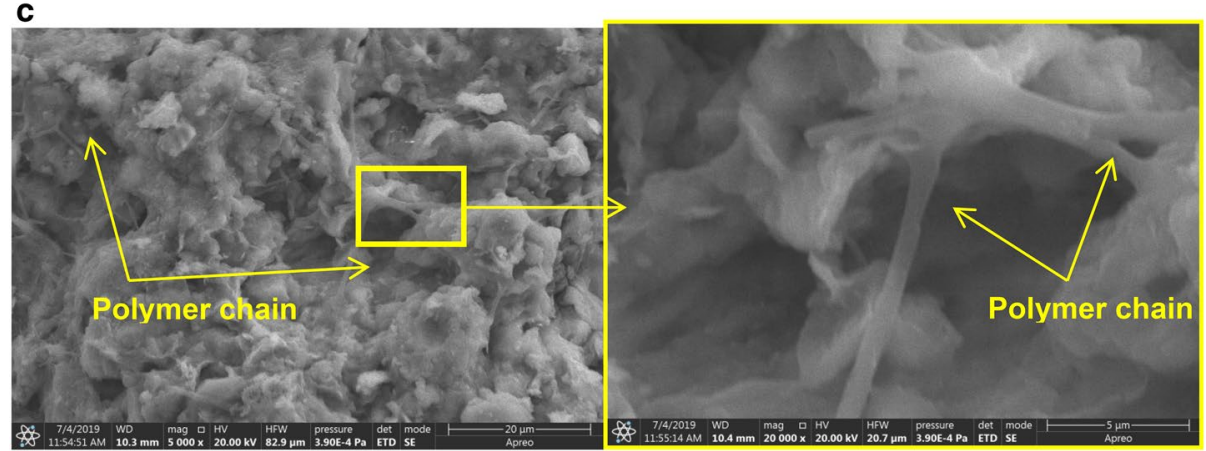

Fig. 3 SEM images of VJS treated with a $0 \% \mathrm{LS}$, b $0.5 \% \mathrm{LS}, \mathbf{c} 1 \% \mathrm{LS}$, d $2 \% \mathrm{LS}$, e $4 \% \mathrm{LS}$

to the reduced thickness of double layer. In addition to that, Fig. 3c-e depicts the formation of polymeric chain microstructure with the increase in percentages of lignosulfonate. It can be seen that the formation of polymer chains increased in VIS with increase in the amount of lignosulfonate.

Micrographs of natural and lignosulfonate treated AMS shown microstructure features similar to VJS. Both the soils consist of montmorillonite as predominant clay mineral, which can be characterized by the presence of undulating filmy particle microstructure [6]. Flocculated or aggregated particle microstructure along with polymeric chains can be evidenced at higher percentages of LS treatment in LS treated AMS as with the case of VJS. Polymer chain breakage can also be evidenced from the Fig. 4d. Lignosulfonate polymer chains bind the soil particles together resulting in the formation of aggregated particles. A similar observation of formation of polymeric chains during the interaction between LS and soil was illustrated by Indraratna et al. [13]. 

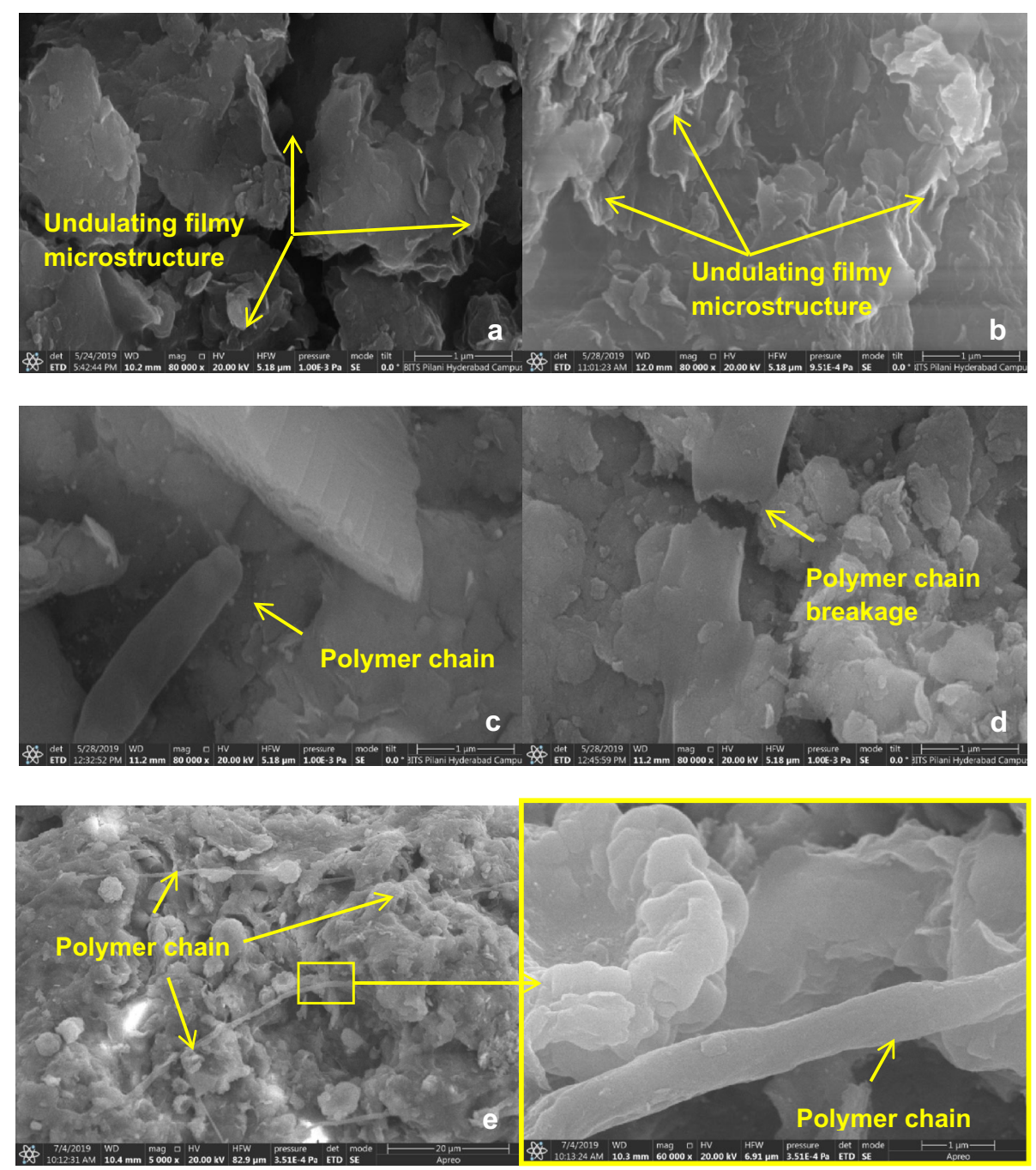

Fig. 4 SEM images of AMS treated with a $0 \% L S$, b $0.5 \% L S$, c $1 \% L S$, d $2 \% L S$, e $4 \%$ LS

\section{Conclusions}

In this study, the characteristics of expansive soils treated with lignosulfonate were assessed. The unconfined compressive strength of soils increased upon treatment with LS. The optimum amount of LS required for treatment of soil as well as the rate of improvement after treatment found to be relying on the amount of fines that soil contains. The CEC of both the expansive soils reduced upon the LS treatment as the negatively charged clay surface area decreased due to presence of positively charged LS solution. SEM micrographs depicted the formation of polymeric chains upon LS treatment. The reduction of negatively charges clay surface by positively charged LS solution followed by formation of polymer chain formations were the possible mechanisms responsible for the improvement in LS treated soils. 


\section{Authors' contributions}

All authors contributed to the final version of the manuscript. RVPC supervised the study, drafted and reviewed the manuscript. BR performed laboratory investigation and analysis. All authors read and approved the final manuscript.

\section{Competing interests}

No conflict of interest.

Received: 27 January 2020 Accepted: 18 August 2020

Published online: 02 November 2020

\section{References}

1. Alazigha DP, Indraratna B, Vinod JS, Ezeajugh LE (2016) The swelling behaviour of lignosulfonate-treated expansive soil. Proc Inst Civil Eng 169(3):182-193

2. Alazigha DP, Vinod JS, Indraratna B, Heitor A (2018) Potential use of lignosulfonate for expansive soil stabilization Environ Geotech 6(7):480-488

3. Arel HŞ (2017) The effect of lignosulfonates on concretes produced with cements of variable fineness and calcium aluminate content. Constr Build Mater 131:347-360

4. Aro T, Fatehi P (2017) Production and application of lignosulfonates and sulfonated lignin. Chemsuschem 10(9):1861-1877

5. Blanck G, Cuisinier O, Masrouri F (2014) Soil treatment with organic non-traditional additives for the improvement of earthworks. Acta Geotech 9(6):1111-1122

6. Chavali RVP, Reddy PHP, Murthy VR, Sivapullaiah PV (2018) Swelling characteristics of soils subjected to acid contamination. Soils Found 58(1):110-121

7. Chen Q, Indraratna B, Carter J, Rujikiatkamjorn C (2014) A theoretical and experimental study on the behavior of lignosulfonate-treated sandy silt. Comp Geotech 61:316-327

8. Cokca E, Birand A (1993) Determination of cation exchange capacity of clayey soils by the methylene blue test. Geotech Test J 16(4):518-524

9. Colombo A, Geiker M, Justnes H, Lauten RA, De Weerdt K (2017) On the mechanisms of consumption of calcium lignosulfonate by cement paste. Cement Concrete Res 98:1-9

10. Ding X, Xu G, Kizil M, Zhou W, Guo X (2018) Lignosulfonate treating bauxite residue dust pollution: enhancement of mechanical properties and wind erosion behavior. Water Air Soil Poll. 229(7):214

11. Danner TA, Justnes H, Geiker MR, Lauten RA (2015) Effect of lignosulfonate plasticizers on the hydration of C3A. In: 14th international congress on the chemistry of cement, Beijing, China

12. Dominijanni A, Fratalocchi E, Guarena N, Manassero M, Mazzieri F (2019) Critical issues in the determination of the bentonite cation exchange capacity. Géotech Lett 9(3):205-210

13. Indraratna B, Muttuvel T, Khabbaz H, Armstrong R (2008) Predicting the erosion rate of chemically treated soil using a process simulation apparatus for internal crack erosion. J Geotech Geoenviron 134(6):837-844

14. Indraratna B, Mahamud MAA, Vinod JS (2012) Chemical and mineralogical behaviour of lignosulfonate treated soils. In: GeoCongress 2012: state of the art and practice in geotechnical engineering, pp 1146-1155

15. Koohpeyma HR, Vakili AH, Moayedi H, Panjsetooni A, Nazir R (2013) Investigating the effect of lignosulfonate on erosion rate of the embankments constructed with clayey sand. Sci World J. https://doi.org/10.1155/2013/58746 2

16. Lemes AP, Soto-Oviedo MA, Innocentini Mei LH, Durán N (2015) Processing, chemical structure and morphology of poly (hydroxybutyrate-co-valerate)/lignosulfonate composites. In: Proceedings of the 2 nd Mercosur congress chemical engineering, Enpromer, Rio de Janeiro, Brazil, pp 1-6

17. Li G, Hou X, Ma W, Wang F (2019) Mechanical properties of loess treated by calcium lignosulfonate. Recent advances in geo-environmental engineering, geomechanics and geotechnics, and geohazards. Springer, Cham, pp 287-289

18. Li C, Pan Q, Zhang J, Qin X, Wang Z, Liu L, Pei M (2007) The modification of calcium lignosulfonate and its applications in cementitious materials. J Disper Sci Technol 28(8):1205-1208

19. Maskell D, Walker $P$, Heath A (2012) The compressive strength of lignosulphonate stabilised extruded earth masonry units. Terra, 2012, pp 11 th

20. Niaounakis M (2015) Building and construction applications. William Andrew Publishing, New York. https://doi. org/10.1016/B978-0-323-35399-1.00010-7

21. Noorzad R, Ta'negonbadi B (2018) Mechanical properties of expansive clay stabilized with lignosulfonate. Quart J Eng Geol Hydrogen 51(4):483-492

22. Ouyang X, Qiu X, Chen P (2006) Physicochemical characterization of calcium lignosulfonate-a potentially useful water reducer. Colloid Surf A. 282:489-497

23. Pei X, Zhang F, Wu W, Liang S (2015) Physicochemical and index properties of loess stabilized with lime and fly ash piles. Appl Clay Sci 114:77-84

24. Puppala AJ, Hanchanloet S (1999) Evaluation of a new chemical treatment method on strength and resilient properties of a cohesive soil. Transport. Res. Board: Paper No. 990389

25. Ravishankar AU, Panditharadhya BJ, Reddy KJC, Amulya S (2017) Experimental investigation of lateritic soil treated with calcium lignosulfonate. indian geotechnical conference, GeoNEst, 14-16 December 2017, IIT Guwahati, India

26. Santoni RL, Tingle JS, Webster SL (2002) Stabilization of silty sand with nontraditional additives. Transp. Res Rec 1787:61-70 
27. Sezer A, Mardani-Aghabaglou A, Boz A, Tanrınıan N (2016) An investigation into strength and permittivity of compacted sand-clay mixtures by partial replacement of water with lignosulfonate. Acta Phys Pol A 130(1):23-27

28. Shivashankar R, Thomas BC, Krishnanunni KT, Reddy DV (2019) Slope stability studies of excavated slopes in lateritic formations. Geotech Appl. Springer, Singapore, pp 127-134

29. Sridharan A, Prakash K (1999) Mechanisms controlling the undrained shear strength behaviour of clays. Can Geotech J 36(6):1030-1038

30. Ta'negonbadi B, Noorzad R (2017) Stabilization of clayey soil using lignosulfonate. Transp Geotech 12:45-55

31. Telysheva G, Shulga G (1995) Silicon-containing polycomplexes for protection against wind erosion of sandy soil. J Agric Eng Res 62(4):221-227

32. Tingle J, Santoni R (2003) Stabilization of clay soils with nontraditional additives. Transp Res Rec 1819:72-84

33. Vakili AH, Kaedi M, Mokhberi M, Bin Selamat mr, Salimi M (2018) Treatment of highly dispersive clay by lignosulfonate addition and electroosmosis application. Appl Clay Sci 152:1-8

34. Vinod J, Indraratna B, Mahamud MA (2010) Stabilisation of an erodible soil using a chemical admixture. Proc Inst Civil Eng 163:43-51

35. Wold S, Eriksen TE (2003) Diffusion of lignosulfonate colloids in compacted bentonite. Appl Clay Sci 23(1-4):43-50

\section{Publisher's Note}

Springer Nature remains neutral with regard to jurisdictional claims in published maps and institutional affiliations.

\section{Submit your manuscript to a SpringerOpen ${ }^{\circ}$ journal and benefit from:}

- Convenient online submission

- Rigorous peer review

- Open access: articles freely available online

- High visibility within the field

- Retaining the copyright to your article

Submit your next manuscript at $\gg$ springeropen.com 